\title{
AQUATER Software as a DSS for Irrigation Management in Semi-Arid Mediterranean Areas
}

\author{
Marco Acutis ${ }^{* 1}$, Alessia Perego ${ }^{1}$, Ettore Bernardoni ${ }^{1}$, Michele Rinaldi ${ }^{2}$ \\ ${ }^{1}$ Dipartimento di Produzioni Vegetali, Università di Milano \\ Via Celoria 2, 20133 Milano, Italy \\ ${ }^{2}$ CRA - Unità di Ricerca per i Sistemi Colturali degli Ambienti caldo-aridi \\ Via Celso Ulpiani 5, 70125 Bari, Italy
}

Received: 27 July 2009. Accepted: 6 November 2009.

\begin{abstract}
Irrigation management at district or regional scale can be dealt using ecological process-based models and remote sensing data. Simulation crop models simulate at a certain time step the main biophysical variables determining crop photosynthesis and water consumption rates. The research consists in an integrated approach to combine field data, simulation crop model and remote sensing information. Detailed data sets related to topography, soil, climate and land cover were collected and organized into a Geographic Information System, which is routinely updated with remotely sensed images. The code implementation of these two models allows for an improvement of simulation reliability for the crop types considered in the present study in Mediterranean area. Remote sensing images detected by optical and radar satellite sensors at different spatial scales (from 10 to $50 \mathrm{~m}$ ) have been collected over the analyzed crop cycles. Therefore, remote sensing information about land use and leaf area index (LAI) are assimilated dynamically by the model, to increase the effectiveness of simulation.

The integration of crop and water dynamics models with the updated remote sensing information is a Decision Support Systems, AQUATER software, able to integrate remote sensing images, to estimate crop and soil variables related to drought, and subsequently to assimilate these variables into a simulation model at district scale. The significant final outputs are estimated values of evapotranspiration, plant water status and drought indicators. The present work describes the structure of AQUATER software and reports some application results over 2006 and 2007 cropping seasons in Capitanata, South-East Italy. This region has been divided in simulation units cropped by tomato (Lycopersicon lycopersicum L.), sugar beet (Beta vulgaris L. var. saccharifera) and durum wheat (Triticum durum Desf.). Two types of comparison have been carried out: (i) between some tomato observed and simulated data, and (ii) between "LAI Forcing" and "No LAI Forcing" simulated data. LAI Forcing data have been detected by remote sensing over the crop cycle and over the whole region. The model showed a relevant coherence between observed and simulated data (RRMSE $=32,55,30 \%$ for above ground biomass, LAI and soil water content, respectively). In the case of the application of the LAI Forcing procedure, since simulated LAI are lower than the observed values, as a consequence, simulation results underestimate.
\end{abstract}

Key-words: simulation model, field crops, leaf area index, decision support system, tomato. sugar beet, durum wheat.

\section{Introduction}

Irrigation scheduling is an increasing concern related to the expected returns and the continuous decreasing of the water source availability, especially in Mediterranean environment and in those characterized by water limited availability (Tuberosa et al., 2007). Being the water use efficiency the overall aim in such areas, irrigation scheduling is an important decision problem in agriculture that has a major effect on yield, environment and gross margin in water limited areas (Mateos et al., 2002). Precipitation decreasing (Piccarreta et al., 2006) and industrial and civil water demand, especially in development areas, involve a source limited use. Moreover this topic has an increasing importance according to the climate change forecast (Alcamo et al., 2007). The agricultural economic sustainability mainly in Mediterranean environments, in terms of food production and high

\footnotetext{
* Corresponding Author: Tel. +39 02 50316611; Fax: +39 02 50316575. E-mail address: marco.acutis@unimi.it
} 
quality research, most frequently forces the irrigation water requirement. In semi-arid regions, among the most common crops, only durum wheat crops and autumn-winter cereals do not require water supply (even if in Northern Africa they are often irrigated, Oweis et al., 1998); in fact, others herbaceous and tree crops provide sufficient economic results only if irrigated (e.g. for tomato crop, Lycopersicon lycopersicum L., see Rinaldi et al., 2007b). The reduction of water availability and the increase of its cost can be faced only with rational management of the water resources that includes the prevention of water wasting and losses, but also the use of all the technical resources to increase the global water use efficiency. One of the key points for improving the water use efficiency is to develop a procedure for optimal irrigation scheduling, where irrigation timing and volumes are calculated in a way to avoid at the same time plant water stress and losses due to water percolation below the rooted zone.

At field scale it is possible to obtain an optimal irrigation scheduling through the compilation of hydrologic balance, also with help of simple software (Raes et al., 2006) or through the direct measure of the soil water content or the water potential in soil.

It is difficult to extend this methods at larger scales, mainly for the lack of information about land use and crop management. In this case, procedures related to water management are based on Decision Support Systems (Maton et al., 2005). Large scale water management employ models and Geographical Information System-based approaches can be used to predict water demand for agriculture (Knox et al., 1996; Hartkamp et al., 1999). Two types of models are available: (i) models which provide an estimation based on plant water requirements (Herrero and Casterad, 1999; Mateos et al., 2002; Weatherhead and Knox, 2002) and (ii) models which estimate irrigation demand taking into account farmers' practices (Weatherhead and Knox, 2000; Leenhardt et al., 2004a). MODERATO is one of the latter models, proposed by Bergez et al. (2001, 2002), in which irrigation practices, strategies and decisions have been formalized by a set of decision rules.

The crop water stress are also detectable by remote sensing. The most well-known method, is through the measurement of the surface tem- perature of the vegetation cover. The correlation between the surface temperature and water stress relies on the fact that, when a crop transpires, the evaporated water cools the leaves reaching a surface temperature sometimes below the ambient air temperature (Mendez-Barroso et al., 2008). Moran et al. (1994) developed the water deficit index (WDI). This index combines the normalized difference vegetation index (NDVI) and the surface temperature of the foliage to determine water deficit conditions in a field with partial vegetation cover. Mendez-Barroso et al., (2008), according to such approach, processed four LANDSAT images in order to estimate the spatial and temporal distribution of water deficit index in wheat.

Since crops water requirement is a fundamental variable to be taken into account, it is useful to employ remote sensing data to be integrated with pedological maps and meteorological data available in real time. Remote sensing images are able to provide estimated values of crop biomass (Launay and Guerif, 2005), Leaf Area Index (LAI), (Hoffmann and Blomberg, 2004) and detect land use at certain time steps (Blaes et al., 2005). Moreover they are suitable to provide estimated sowing date and water content in the top soil layer of $5 \mathrm{~cm}$ (Wagner et al., 2009). All these information can be summarized into a simulation crop model to improve simulation (Dente et al., 2006; 2008), as an innovated DSS, dealing with real-time obtained data, identifying water stress risk condition and potential water requirement for crops.

The present work is part of a workpackage of AQUATER project (Rinaldi et al., 2005), which develops an integrated methodological approach in order to improve irrigation water management and provide strategies at territorial scale, employing remote sensing and observed data, in Mediterranean area, characterized by irrigated high-value cropping systems. The developed approach could be deployed in territorial planning as decisional support tool. It is based on innovative technologies such as remote sensing, simulation crop models, GIS (Geographical Information System) to handle distributed meteorological, soil and crop parameters. The model, as an innovated DSS, deals new obtained data when they get available.

The aim of this study is to outline the 
AQUATER software for management of water resources for irrigation in Mediterranean cropping systems.

\section{Materials and methods}

\subsection{Model overview}

The AQUATER software has been developed for the water management optimization in Mediterranean field cropping systems. Such crop simulation model implements several alternatives for each processes, using approach already well known and largely validated in the scientific literature and used for practical application.

The software implementation requires an object oriented language; the software development was based on the Unified Modelling Language (UML) that has demonstrated to be an excellent base for handle complex multiple cell models (Ferrara and Rana, 2006). The software is developed employing, when possible, existing free modules and components. The software frame derives from the integration of interchangeable and extensible components (Rizzoli et al., 2005). Moreover the model is an Oriented Objective Program (OOP) being a set of cooperating objects. In OOP, each object is capable of receiving input data, processing data, and sending output data to other objects as an independent unit with a distinct task. Such programming ensures a strict modularity of the simulation model. The software has been developed for "COM" environment using VB6 language and is in development their porting in "Net" environment using VBNet and $\mathrm{C} \#$ programming languages. The software has to respect several requirements not yet completely developed. New requirements can be added, while others can get not necessary.

The reliability to describe different HRUs (Hydrologic Response Units), characterized by specific soil, crop types and weather data, is the first requirement for a territorial scale software analysis (Flügel, 2006). HRUs, even not geographically contiguous, can be characterized by the same data set. Table 1 shows a set of software requirements, divided in functional categories.

\subsection{Simulated processes}

AQUATER software simulates the crop growth and development, on the basis of STAMINA model (Acutis et al., 2007; Richter et al., 2006). The model is based on gross assimilation of $\mathrm{CO}_{2}$ and on maintenance and growth respiration to get the final net carbon assimilation. This kind of simulation tools are known as the "School of de Wit" crop models (van Ittersum et al., 2003) such as SUCROS (Van Keulen et al., 1982) and the derived WOFOST (Van Keulen and Wolf, 1986; Boogaard et al., 1998). Respect to SUCROS and WOFOST, STAMINA model has been improved for the simulation of the seed germination and emergence, implementing the specific software module "GEme" (Bechini et al., 2004) and for better details in the simulation of radiation interception within the canopy. Effect of water stress (1) is simulated according to Sinclair (1986) and Richter et al. (2001), as follows:

$$
f_{\text {stress }}=\frac{2}{1+\exp \left\{-f_{d}\left(\theta_{\text {rel }}\right)\right\}}-1
$$

Table 1. Functional requirements of the software.

\begin{tabular}{|c|c|c|c|}
\hline Data access & Modelling & Output report & "What-if" analysis \\
\hline $\begin{array}{l}\text { Specific soil parameters } \\
\text { and meteorological data } \\
\text { have to be provided to } \\
\text { each HRU (Hydrological } \\
\text { Response Unit) }\end{array}$ & $\begin{array}{l}\text { Crop water requirement } \\
\text { using FAO56 methodology } \\
\text { or direct estimation of } \\
\text { crop resistance }\end{array}$ & $\begin{array}{l}\text { Water requirement and } \\
\text { water supplied at } \\
\text { territorial scale }\end{array}$ & $\begin{array}{l}\text { Evaluation of crop and } \\
\text { water management based } \\
\text { on historical data }\end{array}$ \\
\hline $\begin{array}{l}\text { Real time updating of } \\
\text { meteorological data }\end{array}$ & $\begin{array}{l}\text { Soil water dynamics } \\
\text { using: cascading; ISBA; } \\
\text { Richards' equation. }\end{array}$ & $\begin{array}{l}\text { Production of shape } \\
\text { files for the main water } \\
\text { and crop variables }\end{array}$ & - \\
\hline $\begin{array}{l}\text { Real time access to } \\
\text { remote information for } \\
\text { LAI forcing }\end{array}$ & $\begin{array}{l}\text { Development and growth } \\
\text { of main Mediterranean } \\
\text { field crops }\end{array}$ & $\begin{array}{l}\text { Real time HRU specific } \\
\text { alerts of water stress } \\
\text { condition }\end{array}$ & - \\
\hline
\end{tabular}


where $\mathrm{f}_{\text {stress }}$ is a reduction factor of the gross $\mathrm{CO}_{2}$ assimilation, $\theta_{\text {rel }}$ is the ratio between the actual soil water content and the soil water content at saturation and $\mathrm{f}_{d}$ is a specific factor (range 4-14) depending by crop, sensitivity to water stress and development stage. The model simulates root water uptake allowing compensation of the different water availability at different depth in soil. Moreover it is characterized by three options to simulate water redistribution into the soil; default option is the finite difference resolution of the Richards' equation according to van Dam and Feddes (2000), as in the SWAP model. This simulation offers the best performance in the soil water content simulation, according to their robust physical basis, and is supported by a high number of researches and application, so can be preferred to others options. Richards' main limitation is related to the long time required for simulation, taking very long time when the number of hydrologic units to simulate is large. The application of the finite difference Richards' equation solution to one hydrologic unit, for one growing season is about 30", using a $2 \mathrm{GHz}$ Pentium dual core processor. Alternatively, two other approaches are available: the cascading (tippingbucket model) and the ISBA approach (Noilhan and Planton, 1989). ISBA is based on forcing-restoring of soil water content and can be derived from the Richards' equation with some simplification: soil is divided in two layers, the first one of few centimeters (usually 10), subject to evaporation process, and the second one of $100 \mathrm{~cm}$. ISBA cannot simulate the effect of root growth in depth and the effects of a shallow water table (usually it is not the case in Mediterranean environments). Even though cascading approach is not physically-based, it is adequate when there is not shallow water table and soil profile is quiet homogeneous. Moreover cascading approach is not well suitable in soil with low permeability.

\subsection{Decision Support System}

The Decision Support System (DSS) has been conceived in the AQUATER simulation model integrated with a GIS software. The required components have been added to the simulation AQUATER in order to link the simulation model to the GIS software, to map the input and output data and to read the database (soil climate, crop and management). The model can read the data stored in shape files (*.SHP format, as defined by ESRI company and used in all the GIS softwares) and to update them with the data concerning the different variables. In addition, in the DSS software a tool for the map representation has been included.

\subsection{Real time access to remote detection infor- mation for forcing and assimilation}

Remote sensing (RS) information can be used in simulation analysis. When land cover data, LAI and crop sowing (or transplanting) date are available, remote detection information can be used in forcing procedure, based on LAI detected values. Then AQUATER model computes a new value of leaves weight, as a function of the specific leaf area (SLA) simulated value; from leaf weight the biomass of the different organs of the plant is computed thorough partition coefficients of dry matter among the different plant organs (that model compute for each phenological development stage), and consequently, the total plant biomass. The model forces the calculation when LAI data are provided by RS. Anyway the effectiveness of this approach is under evaluation, because errors occurring in RS detection. The crop pertaining to each HRU is an external input, based on ground information or on the basis of remote sensing information. Since errors in the identification of the crop can occur, model is able to restart when image analysis indicates that the crop effectively present in a specific HRU is not the one assigned as input.

\subsection{The areas of the case study}

The studied have been identified in Capitanata Plain (Apulia region). Here several field trials have been carried out. Capitanata Plain, covering more than $4000 \mathrm{~km}^{2}$, an experiment was set up including a number of ground measurements of meteorological, soil and vegetation variables at satellite overpass. Ground measurements were made on specific fields in order to calibrate and test procedures for assimilating RS data, while RS measurements were made over the whole experimental area in order to extrapolate assimilation procedures to Capitanata Plain area. The data set used in such model application is related to 2006-2007 cropping seasons of durum wheat (Triticum durum Desf.), 
sugar beet (Beta vulgaris L. var. saccharifera) and tomato (Lycopersicum esculentum L.). The model runs over meteorological site-observed data in order to validate soil water content, above ground biomass and LAI output. Soil characterization has been carried out applying a combined approach, linking multivariate geostatistical technique of cokriging with an algorithm of clustering, based on nonparametric density estimate, according to which a cluster is defined as a region surrounding a local maximum of the multivariate probability density function (Rinaldi et al., 2007a). Pedological and soil organic matter data of the rooted topsoil (0-0.40 $\mathrm{m}$ depth), textural and hydrological parameters, were all submitted to a normalizing transformation, and then analyzed by the multivariate geostatistical technique of cokriging (Castrignanò et al., 2010). The application of the clustering approach to the (co)kriged variables, produced the subdivision of the land into 8 distinct classes.

\section{Results and discussion}

\subsection{Model calibration and validation}

Since AQUATER crop model has been developed on the basis of STAMINA, some STAMINA application results are reminded here. Such crop growth model has been used in previous application in Southern Italy under drought conditions and for irrigated field crops. Richter et al. (2006), report good evaluation indexes of the comparison "simulated vs. measured" with the model used in this research for autumnal sugar beet. This species is hard to be modeled, nevertheless the modeling efficiency for plant and root biomass resulted very satisfactory $\left(\mathrm{R}^{2}=0.99\right)$. This consideration is applicable also to the simulation of leaf area expansion. The values related to sugar beet irrigated according to different irrigation scheduling and with different water stress levels, confirmed the model capability to simulate sugar beet also in water stress conditions, nevertheless modelling efficiency for LAI fall down quickly. In this situation the assimilation and forcing of LAI deriving from external information could improve the model performance.

Finally the STAMINA model simulates adequately a long-term experiment (sunflower and
Foggia 2000-01 - Leaf Area Index

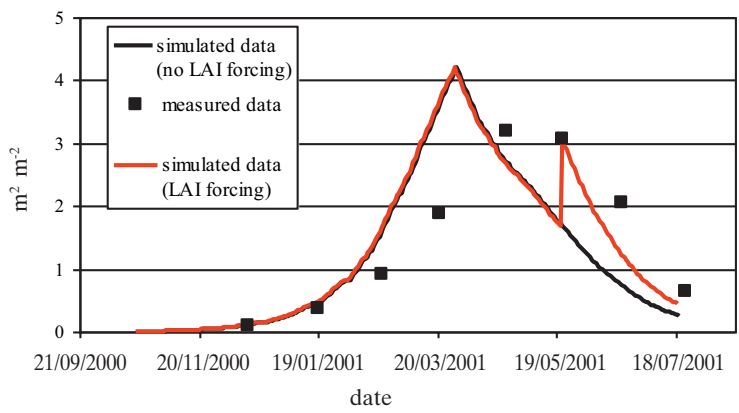

Figure 1. Comparison between measured (ground observation) and simulated values of sugar beet LAI (with and without forcing using remote sensing information). Foggia, 2000/01.

durum wheat), highlighting the validity of proposed approach, not specific for a crop, but that can be used in several cropping systems scenarios (Richter et al., 2006). To simulate new crops, the model needs some input crop parameters (phenological intervals, photosynthesis efficiency, dry matter partition), specific for each new crop the user want simulate.

\subsection{LAI forcing}

In order to evaluate preliminarily the effectiveness of LAI forcing in AQUATER model application, the experimental data previously used in the calibration phase on autumnal sugar beet have been examined. In particular, data from several field trials carried out in Foggia in the 2000/01 and 2001/02 campaigns were used for the calibration (with and without LAI forcing). The criteria to choose the LAI data for testing the effect of forcing was based on the availability of remote sensing images in subsequent years.

In the 2000/01 LAI forcing has been applied just on one date, at the end of April; in the 2001/02 LAI forcing was applied in two dates, on $9^{\text {th }}$ April and on $6^{\text {th }}$ June. In 2000/01, at the date of LAI forcing the LAI was underestimated by the simulation model of about 1.5 , while in 2001/02, the model overestimated the LAI in the first date respect to the measured values; on the contrary, in the second date, the simulated LAI values were greatly underestimated. The results are reported and shown in the Figures 1, 2, 3 and 4.

LAI forcing improved model performance in LAI simulation, affecting positively plant bio- 
Foggia 2000-01 - Root biomass

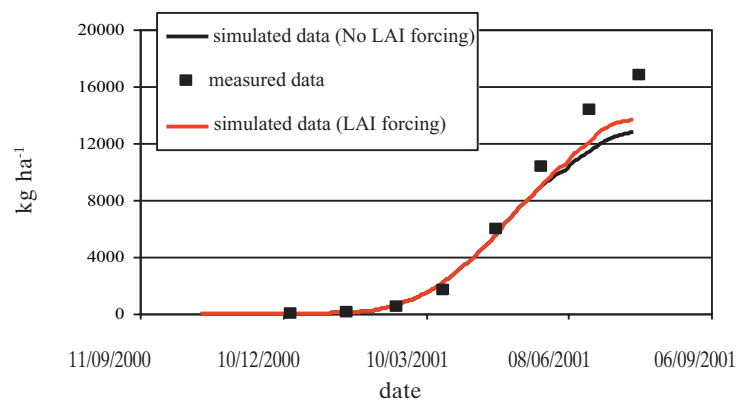

Figure 2. Comparison between measured (ground observation) and simulated values of sugar beet root biomass (with and without forcing using remote sensing information). Foggia, 2000/01.

Foggia 2000-01 - Leaf Area Index

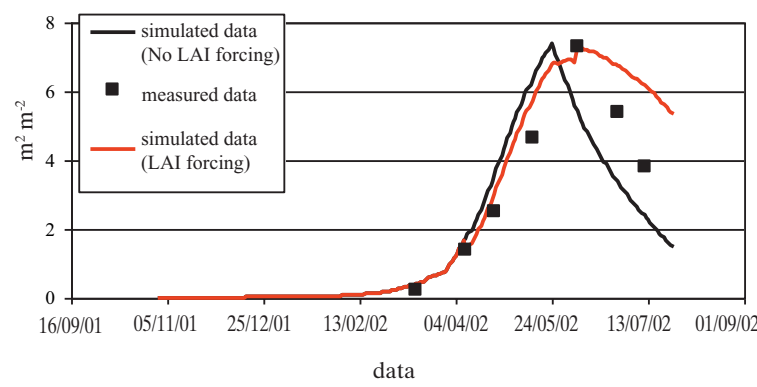

Figure 3. Comparison between measured (ground observation) and simulated values of sugar beet LAI (with and without forcing using remote sensing information). Foggia, 2001/02.

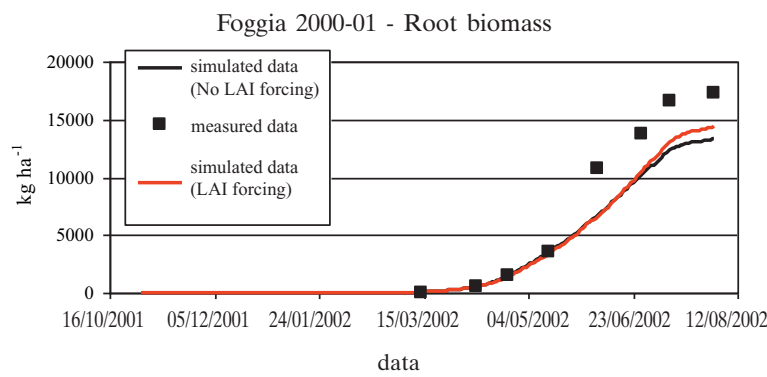

Figure 4. Comparison between measured (ground observation) and simulated values of sugar beet root biomass (with and without forcing using remote sensing information). Foggia, 2001/02.

mass simulation. The results here shown highlighted the useful and positive effects of this assimilation procedure, applying a simulation model capable of reliable estimation of LAI, getting to further improvements by forcing procedure.
As far as AQUATER application in Capitanata is concerned, an example of results at farm scale are reported. The highlighted variables are LAI $\left(\mathrm{m}^{2} \mathrm{~m}^{-2}\right)$, soil water content $\left(\mathrm{SWC}, \mathrm{m}^{3} \mathrm{~m}^{-3}\right)$ and dry matter accumulation $(\mathrm{kg}$ $\left.\mathrm{ha}^{-1}\right)$. As shown in Figure 5, for a tomato crop the model simulates lower values after LAI maximum values was observed, while in the first part of the cycle, the model overestimates the observed data. The Relative Root Mean Squared Error, RRMSE, in this LAI measured and simulated values comparison is $54.9 \%$ and the Coefficient of Determination, CD, is 1.32.

In the case of soil water content, the results shows (Fig. 6) coherence of the model simulation, even though an overestimation trend occurs in the first period of comparison (RRMSE $=30.1 \%, \mathrm{CD}=0.87)$. SWC was simulated without stress due to irrigation shortage. In fact, in Capitanata plain tomato crop is actually irrigated with a large amount of water, with the exception of the first part of the cycle, when irri-

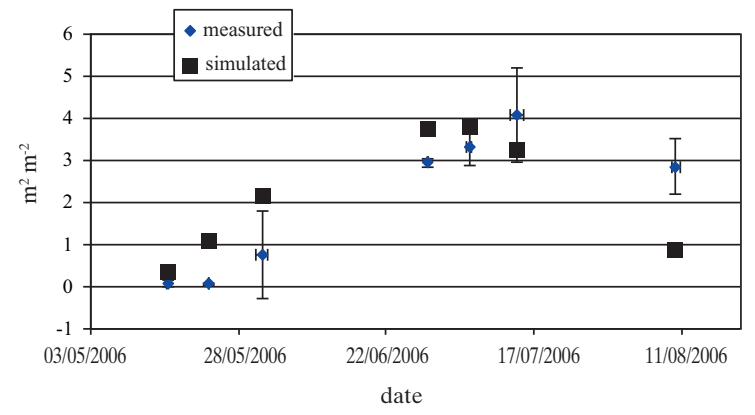

Figure 5. Comparison between measured and simulated LAI values related to tomato crop in 2006 in De Lucretis farm.

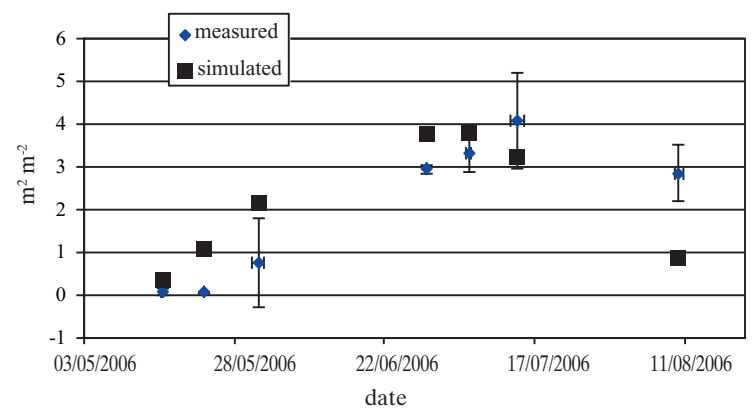

Figure 6. Comparison between measured and simulated SWC values related to tomato crop in 2006 in De Lucretis farm. 


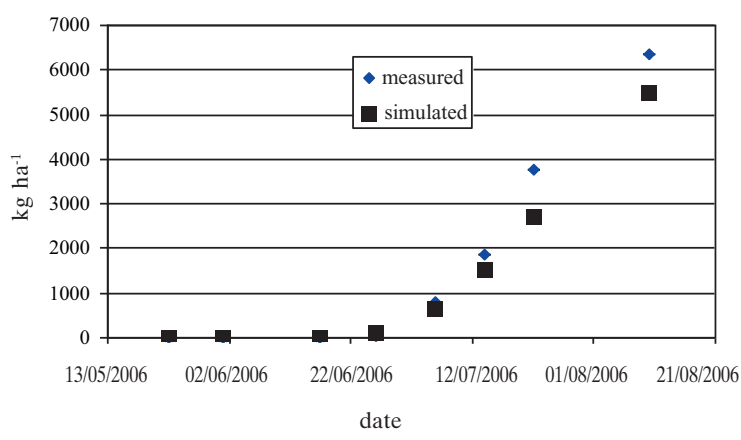

Figure 7. Comparison between measured and simulated dry matter values related to tomato crop in 2006 in De Lucretis farm.

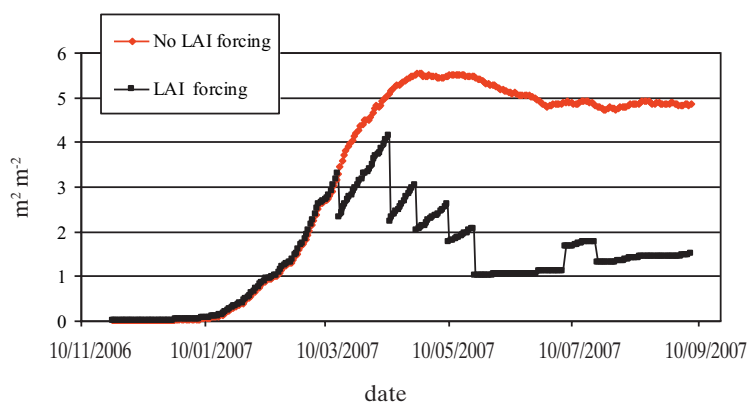

Figure 8. Comparison between simulated LAI values ("no LAI forcing" and "LAI forcing" application) related to sugar beet crop in 2007 in 2316 simulation unit in Capitanata Plain.

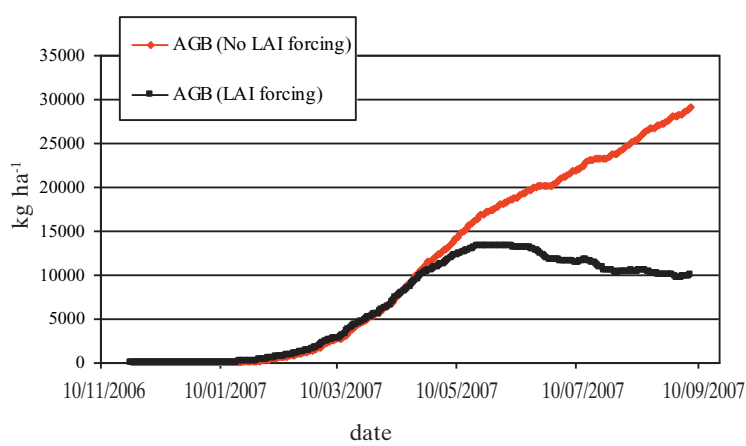

Figure 9. Comparison between simulated dry matter values ("no forcing" and "forcing" application) related to sugar beet crop in 2007 in 2316 simulation unit in Capitanata Plain.

gation is partially supplied in order to assure the root growth in deeper soil layers.

In the case of dry matter accumulation (Fig. 7), there is an almost complete according between measured and simulated values (RRMSE $=31.72 \%$ and $\mathrm{CD}=1.41$ ).

\subsection{Spatial application}

The model has been applied at Capitanata Plain that was first divided in simulation cells, as simulation units, previously identified by taking into account cropping systems. The three most representative crops are tomato, sugar beet and durum wheat.

Here some results of the model application are reported, in particular of sugar beet and durum wheat. The model has run with no forcing LAI values and subsequently applying such values, obtained by remote sensing detection.

With no forcing procedure, as shown in Figure 8, AQUATER model overestimates LAI increasing over the crop cycle in the case of sugar beet. This overestimation leads to higher simulated values of dry matter accumulation, being calculated on the basis of LAI and crop coefficient (Fig. 9). Therefore higher crop water requirements are calculated (Fig. 10). Applying LAI forcing procedure AQUATER model gets to more representative values of water requirement.

As shown in Table 2, definitely lower values of water requirements $(\mathrm{mm})$ are obtained applying AQUATER model with LAI forcing procedure, getting to values even half lower than those obtained in previous application without forcing.

In the case of durum wheat water requirement is not concerned being not a rainfed crop. Nevertheless LAI forcing procedure proves the model underestimation of LAI values (Fig. 11). No changes in dry matter accumulation simulated values are detected as shown in Figure 12. Therefore, when wheat yield forecasts are re-

Table 2. Comparison between simulated crop water requirements values ("no forcing" and "forcing" application) related to sugar beet crop in 2007 in Capitanata Plain. Standard deviation $(\mathrm{SD}, \mathrm{mm})$ and coefficient of variation $(\mathrm{CV}$, $\%)$ indexes are shown.

\begin{tabular}{lccc}
\hline No LAI Forcing & Mean (mm) & SD (mm) & CV (\%) \\
\hline June & 74 & 10 & 13 \\
July & 140 & 10 & 7 \\
August & 140 & 11 & 8 \\
\hline LAI Forcing & & & \\
\hline June & 36 & 7 & 19 \\
July & 58 & 10 & 17 \\
August & 55 & 8 & 14 \\
\hline
\end{tabular}



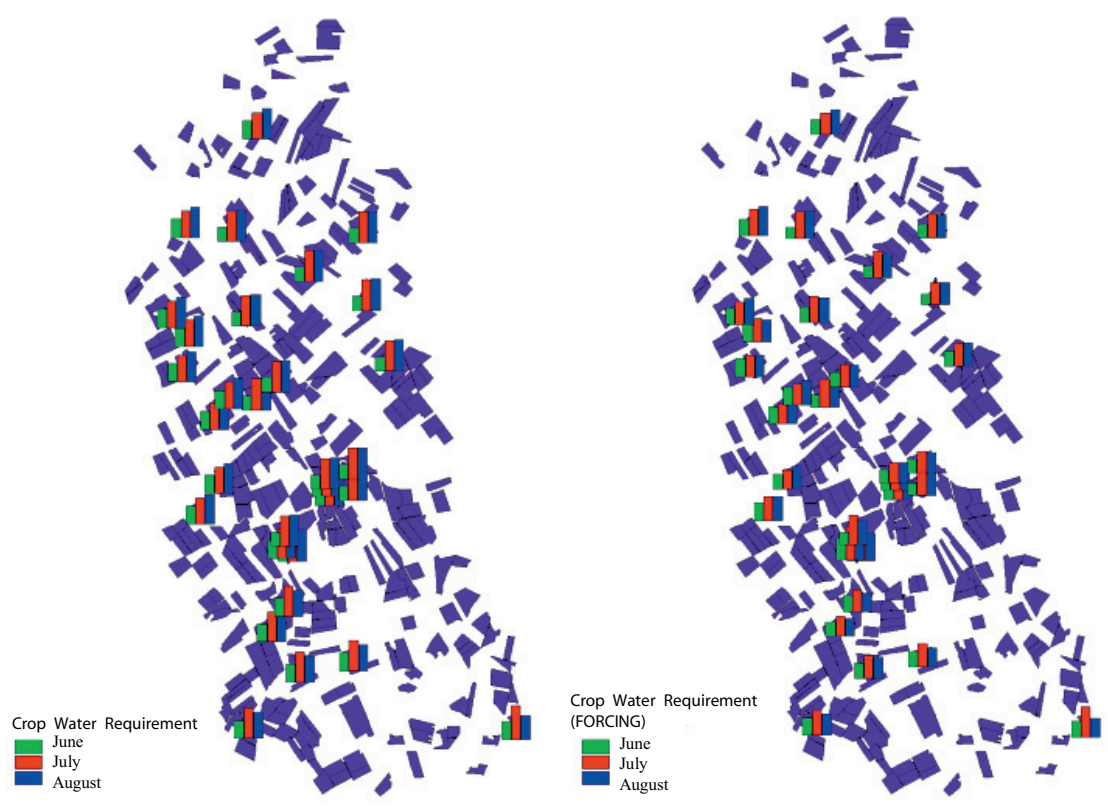

Figure 10. Comparison between simulated crop water requirement ("no forcing" and "forcing" application) of sugar beet crop in 2007 in Capitanata Plain.

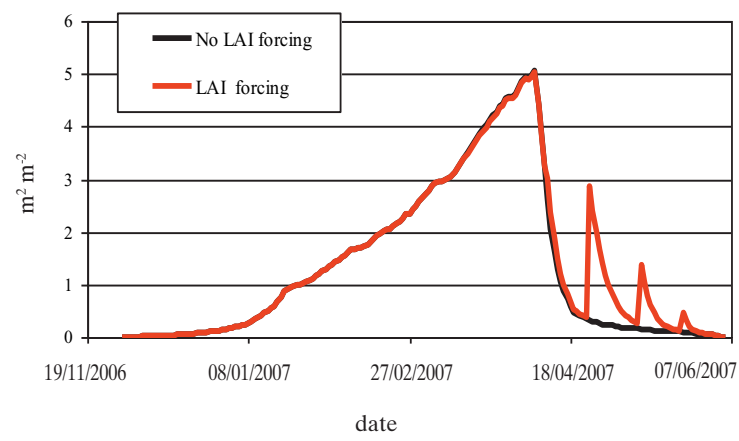

Figure 11. Comparison between simulated LAI values ("no forcing" and "forcing" application) related to durum wheat crop in 2007 in 3339 simulation unit in Capitanata Plain.

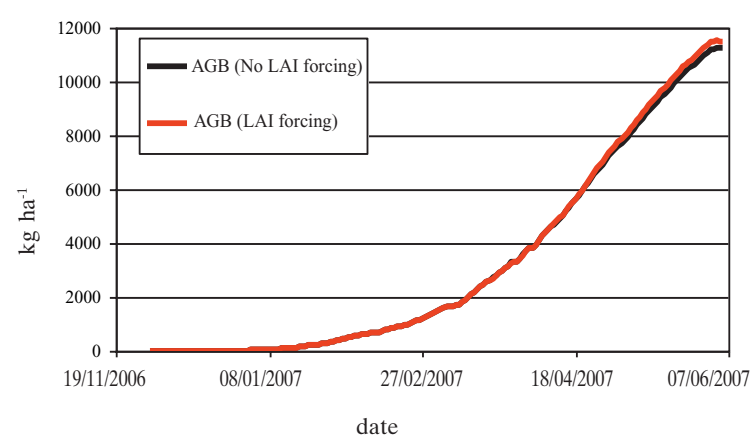

Figure 12. Comparison between simulated dry matter values ("no forcing" and "forcing" application) related to durum wheat crop in 2007 in 3339 simulation unit in Capitanata Plain. quired then LAI forcing seems to be not crucial.

In Figure 13 maximum LAI values for each cell characterized by sugar beet and wheat cropping system in 2007 are shown; durum wheat and sugar beet maximum LAI values are reached at the beginning of April and in the first half of May, respectively. Different results are reported for "no forcing" application and "forcing" application. The overall map related to "forcing" application shows lower values of LAI; durum wheat LAI mean values decrease from 4.9 to 4.7 . This overestimation trend is remarkable for sugar beet crop: sugar beet values LAI mean values decrease from 5.6 to 4.4 (durum wheat simulation units area represent the $90 \%$ of the total amount).

\subsection{DSS Software}

The software viewer is shown (prototype software available version) in Figure 14.

The model is now capable to read the geographic database (shape file format) where, for each simulation unit, the soil characteristics are stored, and further, can use, always for each simulation unit, an agro-climatic station with daily data, as specified by the user.

The model is organized in order to read the data deriving from remote sensing images and to force a specific model dynamic variable.

The software is in test and verification phases. The first trial in order to assimilate the re- 

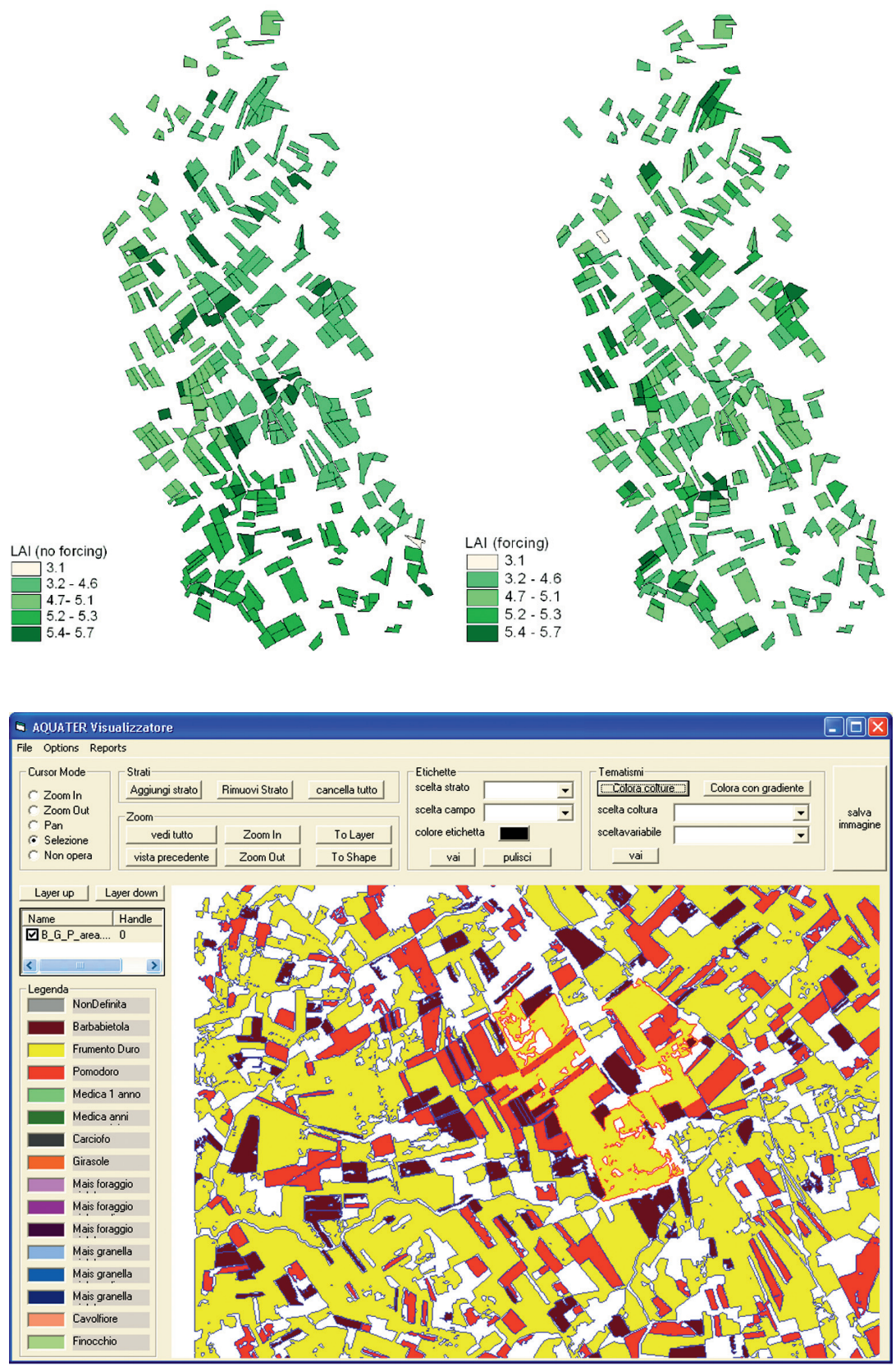

Figure 13. Comparison between simulated maximum LAI values ("no forcing" and "forcing" application) related to durum wheat and sugar beet crops in 2007 in Capitanata Plain.
Figure 14. An example of data viewer of AQUATER software. mote sensing image to estimate sowing dates are in progress. The crop sowing date estimation, with images following the sowing itself, is of great importance, because crop water use and drought effects are dependent by phenology, and, subsequently, by sowing dates and climatic conditions (Acutis et al., 2008).

Sowing date prediction is obtained with a process with iterative approximations, re-starting the simulation by different dates, until to find the one obtaining LAI values closer to that derived by remote sensing images (from NDVI index).

\section{Conclusions}

AQUATER software, as a prototype of a Decision System Support, has been developed in order to schedule irrigation at district level in a Mediterranean area. The DSS integrates the in- 
formation deriving from soil and climatic database with a crop simulation model. It simulates the most representative field crops in Southern Italy. Simulation output variables should be used as useful information to estimate the crop water requirement and irrigation needs at regional level.

The DSS requires a detailed input data set, as pedological, meteorological, crops related data. The sowing date can be derived by remote sensing images. The Leaf Area Index and plant biomass derived from remote sensing, can be further used in the assimilation procedure within the simulation model, to force the model to fit the remote sensing values and to get to an improvement of the simulation results.

The present work highlights that LAI estimated data from remote sensing is really influent on simulated biomass and water consumption. The comparison between the observed and simulated data proved that the model performance has a remarkable improvement when remote sensing simulation are available. Since it is impossible to measure data at ground level at large scale, it is really important that data from remote sensing should be adequately detected with an high space and time resolution.

The AQUATER software implements a GIS visualization tool. The first results and the subsequent application show the capabilities of the model, that could improve by using further crop and soil experimental data. Since the DSS has to be more friendly and easy to use, the improvement of the user interface is also an ongoing imperative.

\section{Acknowledgment}

This work is supported by Italian Ministry of Agriculture, Food and Forestry Policies under contract n. 209/7303/05 (AQUATER Project).

\section{References}

Acutis M., Rana G., Trevisiol P., Bechini L., Laudato M., Ferrara R.M., Richter G.M. 2007. Integrating a spatial micrometeorological model into the risk assessment for arable crops in hilly terrain. In: Kersebaum K.C., Hecker J.M., Mirschel W., Wegehenkel M. (eds.): Modelling water and nutrient dynamics in soil-crop systems. Springer.

Acutis M., Rinaldi M., Mattia F., Perego A. 2008. Integration of a crop simulation model and remote sens- ing information. In: Caos W., White J.W., Wang E. (eds): Crop Modeling and Decision Support, 307-316. Tsinghua University Press and Springer.

Alcamo J., Flörke M., Märker M. 2007. Future long-term changes in global water resources driven by socioeconomic and climatic changes. Hydrol. Sci. J., 49, 4:549-562.

Bechini L., Laudato M., Trevisiol P., Richter G.M., Rinaldi M., Acutis M. 2004. Dynamic simulation model for seed germination, seedling elongation and emergence. Proceedings of VIII Congress of the European Society for Agronomy, Copenhagen, Denmark, 11-15 July 2004, 217-218.

Bergez J.E., Debaeke P., Deunier J.M., Lacroix B., Leenhardt D., Leroy P., Wallach D. 2001. MODERATO: an object-oriented decision tool for designing maize irrigation schedules. Ecol. Model., 137:43-60.

Bergez J.E., Deumier J.M., Lacroix B., Leroy P., Wallach D. 2002. Improving irrigation schedules by using a biophysical and decisional model. Eur. J. Agron., 16:123-135.

Blaes X., Vanhalleb L., Defournya P. 2005. Efficiency of crop identification based on optical and SAR image time series. Remote Sens. Environ., 96, 3-4:352-365.

Boogaard H.L., van Diepen C.A., Rötter R.P., Cabrera J.C.M.A., van Laar H.H. 1998. WOFOST 7.1 User guide for the WOFOST 7.1 crop growth simulation model and WOFOST Control Center 5.1. Techn. Doc. 52, Alterra, WUR, Wageningen, The Netherlands, 144 pp.

Castrignanò A., De Benedetto D., Girone G., Guastaferro F., Sollitto D., 2010. Characterization, Delineation and Visualization of Agroecozones Using Multivariate Geographical Clustering. Ital. J. of Agronomy, 5, 2:121132.

Dente L., Rinaldi M., Mattia F., Satalino G. 2006. Assimilation of polarimetric C-Band Radar data into CERES-Wheat model. Rivista Italiana di Telerilevamento, 35:21-34.

Dente L., Satalino G., Mattia F., Rinaldi M. 2008. Assimilation of Leaf Area Index derived from ASAR and MERIS data into CERES-Wheat model to map wheat yield. Remote Sens. Environ., 112:1395-1407.

Ferrara R.M., Rana G. 2006. Application of the unified modelling language to a spatially distributed micrometeorological model at catchment scale. Ital. J. of Agrometeorology, 1:32-40.

Flügel W.A. 2006. Delineating hydrological response units by geographical information system analyses for regional hydrological modelling using PRMS/MMS in the drainage basin of the River Bröl, Germany. Hydrol. Process., 9, 3-4:423-436.

Hartkamp A.D., White J.W., Hoogenboom G. 1999. Interfacing geographic information systems with agronomic modelling: a review. Agron. J., 91:761-772.

Herrero J., Casterad M.A. 1999. Using satellite and other data to estimate the annual water demand of an irrigation district. Environ. Monit. Assess., 55:305-317.

Hoffmann C.M., Blomberg M. 2004. Estimation of leaf area index of Beta vulgaris L. based on optical remote sensing data. J. Agron, Crop Sci., 190, 3:197-204. 
Knox J.W., Weatherhead E.K., Bradley R.I. 1996. Mapping the spatial distribution of volumetric irrigation water requirements for main crop potatoes in England and Wales. Agric. Water Manage., 31:1-15.

Launay M., Guerif M. 2005. Assimilating remote sensing data into a crop model to improve predictive performance for spatial applications. Agr. Ecosyst. Environ., 111, 1-4:321-339.

Leenhardt D., Trouvat J.L., Gonzales G., Pérarnaud V., Prats S., Bergez J.E. 2004. Estimating irrigation demand for water management on a regional scale. I. ADEAUMIS, a simulation platform based on bio-decisional modelling and spatial information. Agr. Water Manage., 68:207-232.

Mateos L., Lopez-Cortijo I., Sagardoy J. 2002. SIMIS: the FAO decision support system for irrigation scheme management. Agr. Water Manage., 56:193-206.

Maton L., Leenhardt D., Goulard M., Bergez J.E. 2005. Assessing the irrigation strategies over a wide geographical area from structural data about farming systems. Agr. Syst., 86, 3:293-311.

Méndez-Barroso L.M., Garatuza-Payàn J., Vivoni E.R. 2008. Quantifying water stress on wheat using remote sensing in the Yaqui Valley, Sonora, Mexico. Agr. Water Manage., 95:725-736.

Moran S., Clarke T.R., Inoue Y., Vidal A. 1994. Estimating crop water deficit using the relation between surface-air temperature and spectral vegetation index. Remote Sens. of Environ., 46:246-263.

Noilhan J., Planton S. 1989. A simple parameterization of land surface processes for meteorological models, Mon. Wea. Rev., 117:536-549.

Oweis T., Pala M., Ryan J. 1998. Stabilizing rainfed wheat yields with supplemental irrigation and nitrogen in a Mediterranean climate. Agron. J., 90, 5:672-681.

Piccarreta M., Capolongo D., Boenzi F. 2006. Trend analysis of precipitation and drought in Basilicata from 1923 to 2000 within a Southern Italy context. Int. J. Climatol., 24:907-922.

Raes D., Geerts S., Kipkorir E., Wellens J., Sahli A. 2006. Simulation of yield decline as a result of water stress with a robust soil water balance model. Agr. Water Manage., 81, 3:335-357.

Richter G.M., Jaggard K.W., Mitchell R.A.C. 2001. Modelling radiation interception and radiation use efficiency for sugar beet under variable climatic stress. Agric. Forest Meteorol., 109:13-25.

Richter G.M., Rana G., Ferrara R.M., Ventrella D., Acutis M., Trevisiol P., Laudato M., Gusberti D., Mayer Th., Baggeley N., Morris J., Holmes A., Trawick P., Dailey A.G., Robbins P., Simota C., Whitmore A.P., Powlson D.S. 2006. Stability and Mitigation of Arable
Systems in Hilly Landscapes (EU-QLK-5-CT-200201313). Report to the European Commission, Brussels.

Rinaldi M., Castrignanò A., Mastrorilli M., Rana G., Ventrella D., Acutis M., D’Urso G., Mattia F. 2005. Decision support systems to manage water resources at irrigation district level in Southern Italy using remote sensing information. An integrated Project (AQUATER). Proc. of Earth Observation, 10-11 December 2005, Napoli (I), 107-114.

Rinaldi M., Campi P., Castellini M., Ferrara R.M., Fiorentino C., Garofalo P., Satalino G. 2007a. AQUATER project: the measurement campaign in Capitanata plain of soil-plant-atmosphere continuum. Proceedings of $5^{\text {th }}$ International Symposium on Retrieval of Bio- and Geophysical Parameters from SAR Data for Land Applications, 25-28 September, Bari (I), pdf P_05.

Rinaldi M., Ventrella D., Gagliano C. 2007b. Comparison of nitrogen and irrigation strategies in tomato using CROPGRO model. A case study from Southern Italy. Agr. Water Manage., 87:91-105.

Rizzoli A.E., Athanasiadis I.N., Donatelli M., Huber D., Muetzelfeldt R. 2005. Overall architectural design of SeamFrame. SEAMLESS report no. 7.

Sinclair T.R. 1986. Water and nitrogen limitations in soybean grain production. Part I. Model development. Field Crops Res., 15:125-141.

Tuberosa R., Giuliani S., Parry M.A.J., Araus J.L. 2007. Improving water use efficiency in Mediterranean agriculture: what limits the adoption of new technologies? Ann. Appl. Biol., 150, 2:157-162.

van Dam J.C., Feddes R.A. 2000. Numerical simulation of infiltration, evaporation and shallow groundwater levels with the Richards equation. J. Hydrol., 233:72-85.

van Ittersum M.K., Leffelaar P.A., Van Keulen H., Kropff M.J., Bastiaans L., Goudriaan L. 2003. On approaches and applications of the Wageningen crop models. Eur. J. of Agronomy, 18:201-234.

van Keulen H., Penning de Vries F.W.T., Drees E.M. 1982. A summary model for crop growth. In: Penning de Vries, F.W.T., Van Laar, H.H. (eds.), Simulation of Plant Growth and Crop Production. Simulation Monographs. Pudoc, Wageningen, The Netherlands, 87-98.

van Keulen H., Wolf J. 1986. Modelling of agricultural production: weather soils and crops. Simulation Monographs. Pudoc, Wageningen, The Netherlands, 80-86.

Wagner W., Verhoest N.E.C., Ludwig R., Tedesco M. 2009. Remote sensing in hydrological sciences. Hydrol. Earth Syst. Sci., 13:813-817.

Weatherhead E.K., Knox J.W. 2000. Predicting and mapping the future demand for irrigation water in England and Wales. Agr. Water Manage., 43, 2:203-218. 